\title{
EDITORIAL
}

\section{Asthma patient safety incidents: national perspectives need to be informed by primary care reporting}

Sukhmeet Singh Panesara,

Vivian Tanga, Kevin Cleary,

*Aziz Sheikh ${ }^{c}$

${ }^{a}$ Chief Medical Officer Clinical Advisor National Patient Safety Agency

${ }^{b}$ Medical Director, National Patient Safety Agency

c Professor of Primary Care Research \& Development, Allergy \& Respiratory Research Group, Centre for Population Health Sciences: GP Section, University of Edinburgh

*Correspondence:

20 West Richmond Street

Edinburgh, EH8 9DX

E-mail: aziz.sheikh@ed.ac.uk
Medical errors are endemic to healthcare systems. In the USA, for example, they account for an estimated 98,000 preventable patient deaths per year, and in the UK 10\% of hospital patients experience a medical error. ${ }^{1}$ Following increasing awareness of the disease burden associated with errors and the frequency with which particular scenarios repeated themselves, in 1999 the Institute of Medicine recommended the creation of patient safety reporting systems (PSRS) in order to identify the underlying causes thereby aiming to reduce harm from such medical errors. Their landmark report, To Err is Human, together with subsequent contributions, have laid the groundwork for the creation of international databases of safety reports. ${ }^{2.5}$ Considering that the vast majority of patient healthcare encounters take place in primary care, it is essential that primary care professionals engage with these initiatives, which should help drive improvements in the safety of care. However, of the 2,084 asthma reports submitted to the national database of patient safety incidents in England and Wales, $79 \%(n=1,645)$ of these have originated from secondary care with only $7 \%(n=153)$ originating from primary care (see Figure 1).

The National Patient Safety Agency (NPSA) now has, through its Research and Learning Service (RLS), the largest repository of patient safety incidents (PSIS) in the world. This database, established in 2003, receives more than 900,000 reports annually - from the prospective collection of critical incident reports from healthcare staff throughout the NHS,

Figure 1. Asthma reports submitted to the RLS database, 2003-2008.

\begin{tabular}{|c|c|c|c|c|c|c|c|c|c|}
\hline \multirow[t]{3}{*}{ 唡 } & \multicolumn{7}{|c|}{ Degree of harm } & & \\
\hline & \multirow{3}{*}{$\begin{array}{l}\text { No } \\
\text { harm }\end{array}$} & \multirow{3}{*}{ Low } & \multirow{3}{*}{ Moderate } & \multirow{3}{*}{ Severe } & \multirow{2}{*}{\multicolumn{2}{|c|}{\begin{tabular}{|c|} 
Death \\
If a death, \\
recommendation \\
of reviewer for \\
exclusion
\end{tabular}}} & \multirow{3}{*}{ ALL } & & \\
\hline & & & & & & & & & \\
\hline Specialty & & & & & YES & NO & & Total & Percentage \\
\hline Medical specialties & 307 & 88 & 56 & 9 & 2 & 3 & 5 & 465 & 22 \\
\hline Accident and Emergency (A) & 195 & 53 & 36 & 10 & 2 & 4 & 6 & 300 & 14 \\
\hline Other & 183 & 44 & 30 & 6 & 0 & 0 & 0 & 263 & 13 \\
\hline Surgical specialties & 154 & 63 & 29 & 5 & 0 & 2 & 2 & 253 & 12 \\
\hline Obstetrics and gynaecology & 166 & 43 & 28 & 5 & 1 & 0 & 1 & 243 & 12 \\
\hline Primary care / Community & 107 & 24 & 14 & 5 & 0 & 3 & 3 & 153 & 7 \\
\hline Mental health & 58 & 15 & 10 & 2 & 12 & 0 & 12 & 97 & 5 \\
\hline Other specialties & 41 & 18 & 7 & 1 & 0 & 1 & 1 & 68 & 3 \\
\hline Diagnostic services & 29 & 18 & 11 & 1 & 0 & 1 & 1 & 60 & 3 \\
\hline Anaesthetics & 26 & 10 & 4 & 0 & 1 & 0 & 1 & 41 & 2 \\
\hline PTS (Patient Transport Service) & 36 & 2 & 0 & 0 & 0 & 1 & 1 & 39 & 2 \\
\hline \multirow[t]{2}{*}{ Unknown } & 20 & 9 & 7 & 1 & 0 & 0 & 0 & 37 & 2 \\
\hline & 18 & 7 & 3 & 0 & 0 & 0 & 0 & 28 & 1 \\
\hline Not applicable & 9 & 6 & 2 & 0 & 0 & 0 & 0 & 17 & $<1$ \\
\hline Learning disabilities & 2 & 4 & 5 & 0 & 1 & 0 & 1 & 12 & $<1$ \\
\hline $\begin{array}{l}\text { Dentistry - General and } \\
\text { Community }\end{array}$ & 4 & 2 & 2 & 0 & 0 & 0 & 0 & 8 & $<0.5$ \\
\hline Total & 1,355 & 406 & 244 & 45 & 19 & 15 & 34 & 2,084 & 100 \\
\hline
\end{tabular}


and more recently from patients and the general public too. Analyses of these 2.7 million reports are being used to help formulate solutions for identified problems and to inform important national policy decisions. , $^{6}$

Any "unintended or unexpected incident that could have or did lead to harm for one or more patients receiving NHS-funded care" qualifies for reporting. ${ }^{8}$ The RLS database encourages blame-free submission of patient safety incident reports. Two systems exist for reporting PSIs: one via a web-based open-access system; and the more frequently-used method whereby NHS staff submit a PSI report via the organisation's own local risk management system which is then submitted in an anonymous format to the RLS database. The RLS contains around 75 data fields, which mainly involve choosing from a range of categories (e.g. incident categories at two levels, specialty and location of the incident), but importantly, it also contains free-text fields which allow reporters the flexibility to describe an event in considerable detail.

Asthma is now one of the commonest long-term disorders, being responsible for considerable morbidity and mortality. In the UK, for example, it is estimated that 5.4 million people have asthma, the majority of whom continue to experience regular symptoms. ${ }^{9}$ Prescriptions for asthma have increased six-fold in the UK and France since 1980. The total annual cost of asthma care in Europe amounts to approximately $€ 17.7$ billion. ${ }^{10}$ In 2002 , there were over 1,400 deaths from asthma in the UK. Most of these deaths and many of the high number of hospital admissions for asthma each year could have been avoided through better routine and emergency care, avoiding delay in getting help during the attack, or by improved concordance with prescribed medications." There are therefore important generalisable lessons that could be learnt from understanding possible shortcomings in asthma care, but this important knowledge base remains disparate despite the availability of national resources such as the RLS.

It is in our professional and patients' collective interests that primary care professionals in England and Wales engage much more with the RLS than has been the case hitherto (and this is also true with respect to primary care professionals engaging with similar initiatives being set up in other parts of the world). We urge primary care professionals with a particular interest in respiratory medicine to take the lead now in this respect and through so doing help ensure that we fulfil our essential responsibility of primum non nocere.

\section{Acknowledgements}

We are grateful to Paul Dennehy, Information Analyst, and Audrey Lawrence, Interim Senior Statistician, from the NPSA for their help.

\section{Conflict of interest declaration}

AS is an Assistant Editor of the PCRJ, but was not involved in the editorial review of, nor the decision to publish, this article.

\section{References}

1. Chief Medical Officer. On the state of the public health: Annual report of the Chief Medical Officer 2005. Available online at http://www.dh.gov.uk/en/ Publicationsandstatistics/Publications/AnnualReports/DH_4137366 Last accessed on 23rd November 2008

2. Kohn L, Corrigan J, Donaldson M, eds. To Err is Human: Building a Safer Health System. Washington D.C.: Committee on Quality of Health Care in America, Institute of Medicine. National Academy Press, 2000

3. Sheikh A, Hurwitz B. A national database of medical error. $J R$ Soc Med 1999;92(11):554-5.

4. Sheikh A, Hurwitz B. Setting up a database of medical error in general practice: conceptual and methodological considerations. Br J Gen Pract 2001; 51(462):57-60.

5. Sheikh A, Hurwitz B. Reducing error, improving safety. Log of errors is needed. BMJ 2000;321(7259):505. doi:10.1136/bmj.321.7259.505

6. National Reporting and Learning System (NRLS) Data Summary. Patient safety incident reports in the NHS: National Reporting and Learning System Data Summary. Issue 9 - ENGLAND. Available online at http://www.npsa.nhs.uk/ EasySiteWeb/GatewayLink.aspx?alld=18253 Last accessed on 23rd November 2008.

7. Cresswell K, Sheikh A. Lessons from the UK National Patient Safety Agency's National Reporting and Learning System on reducing drug allergies. Prim Care Resp J 2008;17(1):3-4. doi:10.3132/pcrj.2008.00005

8. Merry AF. Safety in anaesthesia: reporting incidents and learning from them. Anaesthesia 2008;63(4):337-9. doi:10.1111/j.1365-2044.2008.05517.x

9. Asthma UK. What is asthma? Available online at http://www.asthma.org.uk/ all_about_asthma/asthma_basics/index.html Last accessed on 6th October 2008

10. Asthma. Burden in Europe. European Lung Foundation. Available online at http://www.european-lung-foundation.org/index.php?id=46 Last accessed on 6th October 2008

11. Asthma UK. Where do we stand? Asthma in the UK today. Available online at http://www.asthma.org.uk/search_clicks.rm?id=18\&destinationtype=2\&instan ceid=243007 Last accessed on 23rd November 2008

\section{Available online at http://www.thepcrj.org}

